\title{
Actividad antiinflamatoria de la enzima superóxido dismutasa (SOD), purificada de la especie Allium sativum (ajo)
}

\author{
Mercedes Soberón, Silvia Suárez, Inés Arnao, Emilio Guija, Luzmila Troncoso, Luis Rojas, \\ İtalo Saldaña, Adriana Cordero \\ Centro de Investigación de Bioquímica y Nutrición, Facultad de Medicina, UNMSM
}

Objetivos: Demostrar la actividad antiinflamatoria de la enzima superóxido dismutasa (SOD) purificada de Allium sativum (ajo).

Diseño: Experimental.

Institución: Centro de Investigación de Bioquímica y Nutrición, Facultad de Medicina, UNMSM

Material biológico: Ratas y Allium sativum.

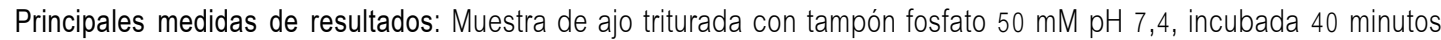
y filtrada; fue sometida a extracción con cloroformo:etanol 1:1 (v/v). Se descartó la fase acuosa. La fase orgánica fue concentrada en un sistema vacio-evaporación a $43-45^{\circ} \mathrm{C}$; se midió actividad de SOD y de proteína. Para la actividad antiinflamatoria in vivo se formó 4 grupos de ratas hembras y se les administró vía subplantar: grupo control ( $\mathrm{NaCl}$ ), referencia (indometacina $10 \mathrm{mg} / \mathrm{kg}$ de peso) y dos grupos con SOD de ajo (extracto crudo y SOD parcialmente purificada). Después de una hora, se inyectó a todos carragenina por vía subplantar. El volumen del edema fue medido con un pletismómetro a los 30,60,120, 180 y 240 minutos.

Resultados: La enzima SOD de ajo fue purificada 1,8 veces. El extracto crudo y el SOD parcialmente purificado no lograron reducir la acción inflamatoria producida a nivel local. La indometacina redujo significativamente la inflamación desde las 2 horas.

Conclusiones: El extracto crudo y la SOD parcialmente purificada, en este modelo, no presentaron actividad antiinflamatoria local.

Palabras clave: Superóxido dismutasa, Allium sativum, ajo.

\section{Potencial antioxidante de 62 variedades de papas nativas del sur andino del Perú}

Silvia Suárez, Juan Trabucco, Raquel Oré, Inés Arnao, Luis Rojas, Jesús Ramírez Centro de Investigación de Bioquímica y Nutrición, Facultad de Medicina, UNMSM

Objetivos: Evaluar la capacidad antioxidante total y el contenido de metabolitos secundarios antioxidantes en papas nativas.

Diseño: Estudio descriptivo.

Institución: Centro de Investigación de Bioquímica y Nutrición, Facultad de Medicina, UNMSM.

Material biológico: 62 variedades de papas nativas (Solanum tuberosum) proporcionadas por el Centro Internacional de la Papa.

Intervenciones: Se preparó extractos hidroalcohólicos de papas nativas frescas. Se determinó la materia soluble y la densidad aparente.

Principales medidas de resultados: La capacidad antioxidante fue determinada mediante la captación de los radicales libres DPPH y ABTS.+. Para los polifenoles y antocianinas se empleó el reactivo de Folin Ciocalteau y por absorbancia diferencial a $\mathrm{pH} 1$ y $\mathrm{pH} 4,5$, respectivamente.

Resultados: Los valores de TEAC-ABTS de las 62 muestras estuvieron entre 3,8 y $47,6 \mathrm{mmol} \%$ de materia soluble y los de TEAC-DPPH se hallaron entre 2,8 y 32,1 umol/g de materia soluble. Las 15 mejores variedades en contenido de polifenoles tuvieron de 1,03 a 2,24 g EAG/L; en este mismo grupo, las antocianinas tuvieron de 30,9 a 204,3 mg/L. El coeficiente de correlación (CC) de TEAC-ABTS y TEAC-DPPH fue 0,91; el CC de polifenoles-antocianinas fue 0,926.

Conclusiones: Las papas nativas constituyen fuentes potenciales de antioxidantes mediados por la composición de metabolitos antioxidantes, como antocianinas y polifenoles, en general.

Palabras clave: Papas nativas, antioxidantes, DPPH, ABTS, polifenoles, antocianinas. 